\title{
PODRŠKA RAZVOJU POTENCIJALNE DAROVITOSTI U PORODIČNOM I INSTITUCIONALNOM KONTEKSTU1
}

\begin{abstract}
Apstrakt: U radu se polazi od stanovišta da kvalitetna iskustva u porodičnom i institucionalnom kontekstu predstavljaju veoma značajne determinante ostvarenja darovitosti. U tom okviru, istaknuta je činjenica da je poslednjih nekoliko decenija došlo do smene paradigmi u oblasti vaspitanja i obrazovanja: od diskursa akademskog postignuća ka diskursu razvoja čoveka, od tradicionalnog ka konstruktivističkom pristupu vaspitanju i obrazovanju. Takođe, ukazuje se i na činjenicu da savremenu pedagošku scenu karakterišu i nova shvatanja deteta, kao i promišljanja značenja te nove slike za vaspitanje i obrazovanje, što otvara potrebu za kreiranjem okruženja učenja koje podstiče dečju radoznalost i interes za svet i za drugoga. U svetlu navedenih postavki, cilj rada usmeren je na sagledavanje mogućnosti pružanja adekvatne vaspitno-obrazovne podrške potencijalno darovitoj deci u porodičnom i institucionalnom kontekstu. Pritom se naglašava da efikasan odnos saradnje porodice i vaspitno-obrazovne institucije, zasnovan na konceptu partnerstva, predstavlja veoma važan činilac razvoja potencijalno darovite dece. Zaključuje se da vaspitanje i obrazovanje potencijalno darovitog deteta zahteva osetljivost na posebne izazove sa kojima se on suočava i volju da se radi zajedno sa ostalim odraslim osobama koje se bave detetom.
\end{abstract} odnos.

Ključne reči: razvoj darovitosti, dete, porodica, vaspitno-obrazovna institucija, partnerski

\section{UVOD}

Jedan od velikih izazova sa kojim se suočavaju savremena društva odnosi se na zadovoljenje potreba darovite dece. Razlog podržavanja darovitih u obrazovnoj politici ima barem dva argumenta: ekonomski prosperitet zemlje i pravičnost. Naime, napredak jedne zemlje nedvosmisleno zavisi od populacije koja je naučno pismena, ali takođe zavisi i od ljudi koji su vodeći stručnjaci u svojoj oblasti, koji

dr Slađana Zuković, e-mail: sladjanaz71@gmail.com

Rad je nastao u okviru projekta „Kvalitet obrazovnog sistema Srbije u evropskoj perspektivi“ (br. 179010) koji u periodu od 2011. do 2015. godine finansira Ministarstvo prosvete, nauke i tehnološkog razvoja Republike Srbije i projekta „Inkluzivno obrazovanje: od pedagoške teorije do prakse” (br. 114-4512050/2011) koji delom finansira Sekretarijat za nauku i tehnološki razvoj AP Vojvodine. 
kreiraju znanje i koji mogu doprineti rešavanju problema sa kojima će se čovečanstvo susretati u budućnosti. Sa druge strane, demokratizacija društva zahteva i demokratizaciju obrazovanja (Zuković \& Milutinović, 2006). Važna je i činjenica da osnovno ljudsko pravo svakog pojedinca u civilizovanom društvu predstavlja mogućnost da razvije svoje pune potencijale (George, 2005). Postoje dalji razlozi zbog kojih je neophodno pružiti podršku darovitoj deci. Reč je o tome da nasleđe može pojedinca snabdeti sa raznim vrstama izuzetnosti, ali to nije dovoljno. Kvalitetna iskustva u porodičnom i institucionalnom kontekstu se danas posmatraju kao veoma značajne determinante ostvarenja darovitosti.

Navedeno ukazuje da se kao ključno otvara pitanje kako potencijalno darovitoj deci pružiti odgovarajuću podršku u razvijanju i ispoljavanju njihovih mogućnosti i sposobnosti na najvišem mogućem nivou. U tom kontekstu, važno je napomenuti da je poslednjih nekoliko decenija u oblasti vaspitanja i obrazovanja došlo do smene paradigmi: od diskursa akademskog postignuća ka diskursu razvoja čoveka, od tradicionalnog ka konstruktivističkom pristupu vaspitanju i obrazovanju. Savremenu pedagošku scenu karakterišu i nova shvatanja deteta, kao i promišljanja značenja te nove slike za vaspitanje i obrazovanje (Bašić, 2011). Ovi novi pristupi nameću potrebu razumevanja, istraživanja i menjanja postojeće vaspitnoobrazovne prakse i okruženja u kojima potencijalno darovita deca žive u porodici i vaspitno-obrazovnim ustanovama. U tom smislu, cilj ovog rada odnosi se na sagledavanje mogućnosti pružanja adekvatne vaspitno-obrazovne podrške potencijalno darovitoj deci, kako u porodičnom, tako i u institucionalnom kontekstu. Pri tome se efikasan odnos saradnje porodice i vaspitno-obrazovne institucije, zasnovan na konceptu partnertva, posmatra kao važan činilac razvoja potencijalno darovite dece.

\section{PROMENA OBRAZOVNIH PARADIGMI I NOVA SHVATANJA DETETA}

U analizi kvaliteta obrazovanja danas se tradicionalnom pedagoškom diskursu akademskog postignuća suprotstavlja diskurs razvoja čoveka koji predstavlja pristup vaspitanju i obrazovanju sa stanovišta razvoja ljudskih bića na kognitivnom, emocionalnom, socijalnom, moralnom i duhovnom nivou (Armstrong, 2008). Diskurs razvoja čoveka zahteva prilagođavanje vaspitno-obrazovnog rada potrebama, interesovanjima i sposobnostima dece, kao i kreiranje uslova kako bi svako dete moglo da ostvari svoje potencijale. Posebno se naglašava potreba da se velika pažnja posveti ogromnim kvalitativnim razlikama koje postoje u fizičkom, emocionalnom, kognitivnom i duhovnom svetu između mlađe i starije dece. Razvojno primerena praksa se više ne tiče pitanja s kojim oblicima vaspitnoobrazovne prakse deca određenog uzrasta treba da se bave, nego sa kojim se praksama ona $m o g u$ baviti. Pomak prema diskursu razvoja čoveka označava i napuštanje uske definicije učenja i povratak idejama velikih mislilaca koji su se bavili vaspitno-obrazovnom praksom tokom poslednjih sto godina (Montesori, Pijaže, Štajner, Erikson, Djui), kao i usmeravanje pažnje ka najnovijim nalazima 
o tome kako se razvija ljudski mozak. Naime, načini na koje mlađe dete prihvata svet umnogome predstavlja odraz onoga što se dešava na neurološkom nivou. Mlađe dete raspolaže obiljem dendrita u kojima dolazi do procesa promena. Veze neurona se pojačavaju ili prekidaju, u zavisnosti od tipa podražaja koje dete dobija ili ne dobija iz okoline (Chugani, prema: Armstrong, 2008). Neurobiologija i rezultati istraživanja odojčadi pokazuju da struktura mozga i dečje mišljenje ne slede jednu individualnu ili kolektivnu razvojnu crtu, nego da reflektuju iskustva koja dete ima u svom sociokulturnom okruženju (Bašić, 2011). Sve to ukazuje na značenje konteksta odrastanja za celokupan dečji razvoj.

Interes za proučavanje kvaliteta konteksta odrastanja podstaknut je, između ostalog, uobličavanjem socijalno konstruktivističke teorije učenja prema kojoj se mentalna aktivnost deteta ne može odvojiti od socijalnog i kulturnog konteksta. Reč je o tome da, za razliku od stanovišta naučnog realizma koji podrazumeva nezavisno postojanje stvarnog prirodnog sveta, sa gledišta socijalnog konstruktivizma znanje o stvarnosti i njeno poimanje nastaju kao posledica čovekovih akcija i tvorenja (Ristić, 2006). Osnovna pretpostavka socijalnog konstruktivizma jeste da stvarnost oblikuju društveni akteri u svakodnevnim interakcijama, a posebno pomoću upotrebe jezika i drugih simboličkih formi. Ova pretpostavka sugeriše da ne postoji istina nezavisno od ljudske percepcije koja se može obelodaniti deci na bazi prenošenja i primanja informacija. Iz ovoga, pak, proizlazi shvatanje učenja kao aktivne konstrukcije stvarnosti koja nastaje u interakciji pojedinca sa socijalnim i fizičkim okruženjem. Za razliku od tradicionalne paradigme vaspitanja i obrazovanja, koja na dete gleda kao na pasivnog primalaca znanja, kao na onoga koji ne zna i kojeg odrasli trebaju da nauče, savremena socijalno konstruktivistička paradigma govori o detetu kao o aktivnom, kreativnom i kompetentnom biću koje na svoj jedinstveni način konstruiše i kokonstruiše svoje znanje, i utiče na vlastiti razvoj (Maleš, 2011). Socijalni konstruktivizam tako reflektuje teoriju dečjeg razvoja koja individualno smešta u određeni sociokulturni kontekst (Milutinović, 2011). Ključne promene u razvoju deteta dešavaju se u socijalnim procesima koji omogućavaju deljenje značenja unutar grupe i njihovo internalizovanje od strane pojedinačnih članova. Kroz interakciju u društvenom okruženju dete istovremeno razvija vlastita značenja i pomaže drugima u otkrivanju značenja. Interaktivni odnosi među svim učesnicima vaspitno-obrazovnog procesa doprinose zajedničkom izgrađivanju znanja.

Savremena pedagogija detinjstva, takođe, posmatra dete kao aktivno i kompetentno biće, koje se na sasvim individualan i biografski jedinstven način uključuje u socijalni kontekst (Bašić, 2011). Nova slika deteta oslanja se na ideje reformske pedagogije s kraja 19. i početka 20. veka, kao i na najnovija istraživanja ljudskog mozga, otkrivanja značaja emocionalne inteligencije, čulnog iskustva, doživljajnog opažanja i empirijske uvide u proces odrastanja. Odlučujuće za savremenu sliku deteta je mišljenje da dete u prvim godinama života usvaja vodeće saznajne modele iz svog okruženja, kao i shvatanje da sociokulturni procesi određuju puteve i obrasce stupanja u kontakt sa svetom i njegovog razumevanja. To 
dovodi do poimanja vaspitno-obrazovnog rada kao kompleksnog procesa podržavanja individualnog razvoja, koji ne nastaje samo iz dečjih mogućnosti, niti jednostavno reflektuje sociokulturne obrasce. $S$ jedne strane, dete donosi vlastite potencijale, a s druge, ono ih razvija i diferencira u kontekstu datih okolnosti. Oslanjanje na novu pedagošku sliku deteta pretpostavlja kreiranje socijalnih i prirodnih uslova za upoznavanje, isprobavanje i razvijanje individualnih mogućnosti. Radi se o potrebi za kreiranjem okruženja učenja koje podstiče dečju radoznalost $\mathrm{i}$ interes za svet $\mathrm{i}$ za drugoga, ali i onog u kojem se dete oseća sigurno i zaštićeno. Odrasli su u tom procesu veoma važni, ali ne kao „prenosioci znanja”, nego kao aranžeri životnih situacija i svakodnevice koja će omogućiti detetu osećaj sigurnosti i ohrabriti ga za istraživanje i razumevanje okruženja (Bašić, 2011: 33).

\section{PORODIČNI KONTEKST RAZVOJA POTENCIJALNO DAROVITE DECE}

Savremene tendencije u oblasti istraživanja darovitosti polaze od stanovišta da je fenomen darovitosti razvojni proces koji je u značajnoj meri determinisan specifičnošču različitih sredinskih faktora. Posebno inspirativno istraživačko polje u ovoj oblasti predstavlja porodica kao primarno razvojno okruženje koje nudi najveće mogućnosti za personalizovanje prostora potencijalno darovitog deteta (Zuković, Milutinović, 2013). Iako su brojne empirijske studije potvrdile esencijalnu ulogu porodice kao sredinskog faktora razvoja ličnosti, važno je imati u vidu da porodica predstavlja složen sistem čije je funkcionisanje determinisano kako unutarporodičnim, tako i vanporodičnim kontekstom (Zuković, 2012a), što u velikoj meri uslovljava i razvoj potencijalno darovitog deteta. Takođe, u relevantnoj literaturi (Freeman, 2000) se naglašava da je teško odrediti idealni tip porodice za razvoj darovitosti. U tom smislu, neki autori (Sekulić-Majurec, 1995) ističu da su se oko pitanja kako i koliko porodica može uticati na razvoj i izražavanje darovitosti formirala određena stanovišta koje je moguće posmatrati kao svojevrsne mitove. Reč je o sledećim shvatanjima: darovitost je u potpunosti određena nasleđem; darovitost se dominantno razvija pod uticajem vaspitanja i obrazovanja; daroviti pojedinci češće potiču iz porodica višeg socio-ekonomskog statusa i višeg obrazovnog nivoa roditelja; redosled rađanja i broj dece u porodici je od presudnog značaja za razvoj darovitosti; da bi se razvila darovitost važno je da roditelji što ranije prepoznaju znakove darovitosti kod svog deteta; u podsticanju razvoja darovitosti najvažnije su prve dve do tri godine života; za razvoj darovitosti važno je da roditelji imaju visoka očekivanja od svog deteta; roditelji koji se dovoljno bave svojim detetom mogu podstaći razvoj njegove darovitosti; zahtevniji i dosledniji roditelji uspešnije podstiču razvoj darovitosti kod svog deteta; važno je da roditelj redovno poučava svoje dete kako bi ono postalo darovito. Neka od pomenutih stanovišta savremena naučna istraživanja potvrđuju, neke delimično potvrđuju, a neke u potpunosti odbacuju (opširnije u: Sekulić-Majurec, 1995). No, bez obzira što neka od uvreženih shvatanja savremena istraživanja posmatraju kao mitove, nesporno je da razvoj potencijalne darovitosti deteta u velikoj meri 
zavisi od karakteristika porodičnog okruženja. Stoga se sasvim opravdano često postavlja pitanje o tome na koji način porodica treba da pruži odgovarajuću podršku u razvijanju potencijala deteta?

Stručnjaci u ovoj oblasti ističu, pre svega, značaj povoljne i podsticajne porodične klime koja podrazumeva takav kvalitet porodične interakcije u kojoj su prisutni balansiran nivo kohezivnosti i fleksibilnosti, kooperativnost i otvorenost u komunikaciji, efikasne strategije u rešavanju problema i konflikata, kao i uzajamna usklađenost vaspitnih stilova roditelja (Pekić, 2012; Zuković, 2012a). Veoma važan aspekt podsticajnog porodičnog okruženja čini i sistem vrednosti koji se u porodici neguje. Pomenute dimenzije uspešnog funkcionisanja porodičnog sistema u celini u velikoj meri utiču na razvoj i funkcionisanje potencijalno darovitog deteta.

Pored adekvatne porodične klime, izuzetno je važna podrška porodice u obezbeđivanju obogaćene sredine koja je potrebna za razvoj potencijalno darovitog deteta. Činjenica je da vrlo često roditelji kreiraju podsticajnu i obogaćenu okolinu kao odgovor na specifične sposobnosti svog deteta i na njegove zahteve (Rotigel 2003). Međutim, iako neka darovita deca modifikuju vlastito okruženje, većini je ipak potrebna dodatna stimulativna sredina kako bi maksimalizovala vlastite potencijale. Stoga je važno da roditelji:

- posmatraju dete kao individuu - da imaju jasnu procenu socijalnih, emocionalnih, fizičkih i obrazovnih potreba deteta;

- obezbede stimulativno okruženje od najranijeg detinjstva - obezbeđivanje različitih materijala za učenje u kući, kao i porodičnih obilazaka biblioteka, zooloških vrtova, muzeja, galerija, knjižara, pozorišta, parkova i sl.;

- pružaju adekvatan model za identifikaciju - ohrabrivanje deteta putem pružanja modela za ugledanje (roditelji koji i sami vredno rade i koji dosta ulažu u svoje obrazovanje);

- razvijaju radne navike deteta od najmlađeg uzrasta, kao i drugih oblika ponašanja koji su značajni za razvoj darovitosti;

- pružaju izazove putem postavljanja ciljeva zasnovanih na dečjim specifičnim sposobnostima - ohrabrivanje dece da postanu kreativna i produktivna, pomaganje deci da naprave ravnotežu u onome čemu se posvećuju;

- razvijaju dečje samopouzdanje - razvijanje poverenja u sopstvene snage, obezbeđivanje slobode odlučivanja, razvijanje motivisanosti za postavljanje sopstvenih ciljeva, saopštavanje očekivanja deci kroz diskusiju sa njima (Milutinović, Zuković, 2008).

Imajući u vidu neosporan značaj roditeljske uloge u razvoju potencijalne darovitosti deteta, ipak treba naglasiti da roditelji ne stvaraju darovitu decu, već isključivo atmosferu u kojoj dete može izraziti svoju darovitost. Ono u čemu je roditeljska uloga nezamenjiva jeste prepoznavanje potencijala deteta, te adekvatna podrška njegovom razvoju. Međutim, činjenica je da roditelji često nisu dovoljno pripremljeni za podizanje darovitog deteta i da nemaju dovoljno znanja, kako o 
njihovim razvojnim karakteristikama, tako i o uslovima koji su neophodni za njihov optimalan razvoj. Otuda se javlja potreba da za edukacijom roditelja u ovoj oblasti, što treba da bude jedan od ciljeva Programa saradnje sa roditeljima u vaspitno-obrazovnoj instituciji.

\section{INSTITUCIONALNI KONTEKST RAZVOJA POTENCIJALNO DAROVITE DECE}

U literaturi se ukazuje na podatak da su savremena, postmodernistička istraživanja pokazala da kontekst institucije ne predstavlja „,nužno zlo” za dete ranog uzrasta, već da, naprotiv, ima veliki uticaj na razvoj deteta, i da od njegovog kvaliteta u velikoj meri zavisi kvalitet dečjeg iskustva i učenja (Petrović-Sočo, 2011). U osnovi ovih shvatanja nalazi se socijalno konstruktivistička teorija dečjeg učenja i razvoja prema kojoj dete ne uči samo u interakciji sa svojim fizičkim okruženjem, već da je u tom procesu upravo presudno sociokulturno okruženje. Dete se više ne posmatra kao nemoćno biće puno ograničenja, već kao osoba puna potencijala koja u zajedničkim aktivnostima s drugom decom i odraslima kokonstruiše, reflektuje i rekonstruiše svoja znanja. Iz ove perspektive značajno je istaći da razvoj dečjih sposobnosti i potencijala zavisi od okruženja u kojem dete živi i uči. Iako se ne može govoriti o neospornim pravilima prema kojima je moguće odrediti da li je neki kontekst vaspitanja i obrazovanja u ranom detinjstvu primeren dečjem razvoju ili nije, u literaturu se sugeriše niz kriterijuma koji se mogu primenjivati pri razvrstavanju vaspitno-obrazovnog konteksta na kontinuumu od razvojno neprimerenog do razvojno primerenog (Armstrong, 2008: 98). Kao razvojno primereni postupci u ranom detinjstvu se navode: igra bez strogih pravila i prirodna sredina, kratko trajanje dnevnih aktivnosti, neformalno učenje tokom celog vremena, učestvovanje roditelja u aktivnostima ustanove, provođenje najvećeg dela vremena u kretanju i učenju, vođenje pažljive dokumentacije o dečjim iskustvima u vezi s igrom i otkrivanje njihovog unutrašnjeg i spoljašnjeg sveta uz pomoć igre, program usmeren na dete, mnogo nestrukturiranog vremena za dečju igru, prepuštanje deci da sama odaberu vlastite aktivnosti i tako dalje.

Podsticajno i razvojno primereno okruženje može se videti u vrtićima Reggio Emilia, koji predstavljaju primer kako u predškolskim ustanovama može izgledati okruženje u kojem dečja igra predstavlja središte događanja oko kojeg se okreće svako učenje (Armstrong, 2008; Vujičić, 2011). Reč je o pristupu kurikulumu kojeg karakteriše stalno uspostavljanje, preispitivanje i građenje programa koji izrasta iz života, potreba i svojstava konkretnih aktera u njihovoj svakodnevnoj interakciji (Goffin \& Wilson, prema: Klemenović, 2009). Ostvarivanje programa u okviru Reggio pristupa odvija se u formi kratkoročnih i dugoročnih projekata čije teme izrastaju iz specifičnih dečjih interesovanja i potreba (Klemenović, 2009). Projekti se ne planiraju u uobičajenom smislu reči, već se samo predviđaju smerovi koji se mogu, ali i ne moraju ostvariti. U tom procesu važno je sastavljanje grupa dece kao zajednica koje imaju neke zajedničke interese, u kojima će se 
razvijati recipročni odnosi poverenja i saradnje. Uloga odraslih jeste da izazivaju situacije za učenje i pomažu deci da otkriju probleme. Pri tome, odrasli ne nude deci brza rešenja, već im pružaju podršku u postavljanju sve složenijih hipoteza (Miljak, 2007). Učenje i razvoj dece teče u intenzivnoj razmeni ličnih teorija i postavki koje se u zajedničkom radu proveravaju i rekonstruišu, pri čemu se koristi mnoštvo različitih ,,jezika” (crtanje, vajanje, pisanje, dramska igra, ples itd), koji omogućavaju višeslojnu razmenu sa drugima, ali i neophodnu samorefleksiju (Rinaldi, prema: Klemenović, 2009). U tom okviru, moglo bi se konstatovati da Reggio pristup povezuje procese društvene konstrukcije stvarnosti sa dečjim procesima razumevanja.

Značajno je napomenuti da je za razvijanje Reggio Emilia projekata ključna dokumentacija (detaljne beleške, video zapisi, fotografije, zabeležene dečje izjave, crteži i slično), koja se svakodnevno vodi o dečjim predlozima, raspravama i mogućim rešenjima. Dokumentovanje procesa na osnovu kojih se otkrivaju veze i odnosi među događajima, osmišljavaju lična i zajednička iskustva i planiraju nova je veoma važno, jer omogućava promišljanje o kreiranju situacija i uslova za individualno i grupno učenje dece i odraslih. U tom smislu, pedagoška dokumentacija omogućava da se dobro upozna svako dete, da se upozna mala grupa dece koja su se zainteresovala za određeni problem, da se shvate njihove strategije učenja i komuniciranja, i načini rešavanja intelektualnih konflikata. Uz to, ona omogućava da se osmisle načini prevladavanja individualnih teorija i olakša stvaranje zajedničkih (Miljak, 2007: 213). Velika pažnja u okviru Reggio pristupa posvećuje se i izgledu i uređenju prostora kojeg odlikuje mnoštvo pažljivo uređenih i međusobno povezanih celina prilagođenih za rad u većim ili manjim projektima, malih intimnih prostora za individualni rad, kao i prostora za zajedničke igre i druženja. Prostor je obogaćen raznovrsnim materijalima za istraživanje i igru, ali i onim materijalima čija dokumentaciona vrednost daje pun smisao postavci da je prostor u Reggio pristupu treći vaspitač (Klemenović, 2009). Polazni stav jeste da emocionalna sigurnost, povezanost sa prostorom, bliskost i prijateljski odnosi predstavljaju bazične uslove kako bi dete iskazalo potrebu i želju za učenjem (Scarpetti \& Fusari, prema: Vujičić, 2011). Kombinujući važne odlike vaspitnoobrazovnog rada u ranom detinjstvu i u podsticanju darovitosti (projektni, istraživački pristup), Reggio pedagogija predstavlja pristup koji je pogodan za potencijalno darovitu decu ranog uzrasta. U okviru ovog pristupa dete se posmatra kao kompetentna osoba bogata potencijalima, pri čemu se naglasak stavlja na razvoj simboličkih i govornih funkcija i sposobnosti na ranom uzrastu, i njihovom doprinosu razvoju viših nivoa mišljenja (Lai, 2009). Otuda se Reggio pedagogija može označiti kao razvojno primeren pristup koji ne samo da podstiče intelektualni razvoj dece, već neguje višestruke forme reprezentacije znanja, čime polaže temelj za razvoj njihovih raznovrsnih talenataUopšte uzev, kada je reč o podsticanje darovitosti u institucionalnom kontekstu, važno je osigurati da se svakom detetu omogući vaspitanje i obrazovanje koje će maksimalno podsticati razvoj njegovih potencijala. Razvojno primereni postupci su od posebnog značaja, budući da se u 
literaturi (Swinney, 1995) ističe da su potencijalno darovita deca uobičajeno sposobna za samostalna otkrića i pronalaženje novih puteva razumevanja, da brzo i lako uče, da imaju odlično pamćenje i bogatiji rečnik od svojih vršnjaka, da poseduju visoku unutrašnju motivaciju i interes za učenje, kao i veliku potrebu za ovladavanjem nekim specifičnim područjem. Razvojna primerena praksa u slučaju potencijalne darovitosti pretpostavlja, pre svega, oblikovanje bogatog okruženja učenja i podržavanje potrebe za nezavisnošću u učenju. U tom smislu je potencijalno darovitu decu potrebno sistematski podsticati, uz osiguravanje raznovrsnih iskustava koja će im omogućiti da zadovolje potrebu za komunikacijom sa decom koja se nalaze na istom intelektualnom uzrastu, što se može realizovati omogućavanjem provođenja određenog vremena u starijoj grupi, možda tokom pričanja priča ili dramskih aktivnosti. Takođe je veoma važno pružiti mogućnost za razvoj divergentnog mišljenja putem, na primer, osiguravanja širokog raspona obrazovnih iskustava i problema za koje postoji više od jednog tačnog odgovora. Bitno je i podržavanje razvoja sposobnosti da se sarađuje s vršnjacima putem aranžiranja socijalnih situacija u kojima potencijalno daroviti mogu biti lideri, ali ponekad i sledbenici. Kao posebno važno područje se ističe rad sa roditeljima potencijalno darovite dece. Njih je potrebno podržati u nastojanjima da odgovaraju na dečja pitanja i osiguraju mnoge mogućnosti za aktivno intelektualno istraživanje, na primer, u muzejima, naučnim centrima, bibliotekama za decu i tako dalje.

\section{PARTNERSTVO PORODICE I VASPITNO-OBRAZOVNE USTANOVE - OKVIR ZA PODSTICANJE RAZVOJA POTENCIJALNE DAROVITOSTI}

Razvoj potencijalno darovitog deteta podrazumeva kontinuiranu i valjano programski utemeljenu saradnju između porodice i vaspitno-obrazovne institucije. Odnos između porodice i vaspitno-obrazovne ustanove moguće je razmatrati kroz tri paradigme: paradigma paralelnih sistema; paradigma dopune; paradigma podrške (Pavlović Breneselović, 2013).

U paradigmi paralelnih sistema porodica i vaspitno-obrazovna ustanova deluju odvojeno kao nezavisni sistemi različitog delokruga i funkcija. Porodica je korisnik usluga koji delegira na vaspitno-obrazovnu ustanovu odgovornost za obrazovanje svoga deteta. Vaspitno-obrazovna ustanova preuzima odgovornost a za uzvrat očekuje lojalnost roditelja. Idealni odnos među njima opisuje se kao odnos „optimalne socijalne distance" i „nemešanja u tuđi posao".

U paradigmi dopune, društveno organizovano vaspitanje i obrazovanje nadomešćuje deficitarnu obrazovnu funkciju porodice, dok za uzvrat roditelji treba da podupiru funkciju vaspitno-obrazovne ustanove, oslanjajući se na eksperte, postajući objekat poučavanja i učesnik u ostvarivanju njenih funkcija (učešćem u upravljanju, volontiranjem u aktivnostima, radom kod kuće sa decom na projektima i domaćim zadacima...).

U paradigmi podrške - koncept partnerstva, porodica i vaspitno-obrazovna ustanova se posmatraju kao dva međuzavisna i umrežena sistema. Ovaj koncept 
temelji se na postavci da su roditelji i profesionalci upućeni jedni na druge, te da je preko potrebno udružiti snage i resurse u donošenju odluka i preduzimanju aktivnosti u pravcu zajedničkog cilja - kreiranja optimalnih uslova za razvoj $i$ učenje dece. Pri tome se, pored eksperata - stručnjaka u vaspitno-obrazovnim ustanovama, i roditelji vide kao eksperti za svoju decu koji najbolje znaju šta je njihovom detetu potrebno.

Jasno je da paradigma podrške, to jest koncept partnerstva porodice i vaspitnoobrazovne institucije, predstavlja najpogodniji okvir za podsticanje razvoja kreativnih i kognitivnih potencijala deteta. Nezaobilazan teorijski okvir za razumevanje međuzavisnog delovanja između porodice i vaspitno-obrazovne ustanove predstavlja ekosistemski pristup koji ilustruje da su uticaji kojima je pojedinac izložen unutar jednog ili kroz interakciju više sistema višestruki i miltidimenzionalni (Cowan et al., 2004; Zuković, 2012a). Posebno su relevantna četiri sistemska principa:

- Princip cirkularne kauzalnosti - promene kod jedne individue utiču na promene i kod drugih individua u sistemu, kao i na promene sistema kao celine. Tako, na primer, aktivnosti i dešavanja u vaspitno-obrazovnoj instituciji utiču na ponašanje dece u porodici, i obratno, dešavanja i različite okolnosti u porodici utiču na ponašanje detata u vaspitno-obrazovnoj instituciji.

- Princip nesumativnosti - sistem kao celina veći je od zbira njegovih delova. To znači da se koordinacijom između porodice i vaspitno-obrazovne institucije postiže širi sinergični odnos, što podrazumeva da vaspitnoobrazovna institucija i porodica zajedno mogu mnogo više da postignu nego kada pojedinačno deluju.

- Principu ekvifinalnosti - isti rezultat može biti posledica različitih preduslova. Na primer, deca koji postižu visoka postignuća mogu poticati iz porodica sa različitim vaspitnim stilovima. Jednostavno rečeno, ne postoji samo jedan put za postizanje određenog cilja.

- Princip multifinalnosti - slični početni uslovi mogu dovesti do različitih kranjih ishoda. Naprimer, slične strategije poučavanja koje se primenjuju u porodici ili vaspitno-obrazovnoj instituciji mogu imati različite efekte na odnos dece prema učenju, što znači da određeni metod poučavanja kod neke dece može rezultirati željenim ciljem, dok kod neke ne (Christenson, 2004).

Navedeni principi potkrepljuju stanovište o neophodnosti kvalitetne i kontinuirane saradnje porodice i vaspitno-obrazovne ustanove, jer, kao bazična okruženja za funkcionisanje deteta, imaju zajednički interes ali i podeljenu odgovornost da udruženim snagama podsticajno deluju na razvoj svakog deteta. Inicijativa za ovakav pristup u saradnji treba da potekne od strane vaspitno-obrazovne institucije i to kroz: 1) Usmerenost na građenje poverenja - preispitivanje vlastite prakse od strane vaspitača/nastavnika: Koliko sam blagonaklon/a i otvoren/a prema roditeljima i deci? U čemu se ogleda moja kompetentnost i kako 
da je unapredim? Na koji način gradim poverenje?; 2) Usmerenost na promenu modela moći - od modela „vladavine moći” (koji je hijerarhijski, linearan i takmičarski) ka modelu „sloboda od moći” (koji je korporativan, demokratski i kolaborativan); 3) Usmerenost na dobrodošlicu porodici - građenje uslova da se roditelji osećaju pozvanim i dobrodošlim za uključivanje u različite aktivnosti. Ovaj aspekt podrazumeva preispitivanje vlastitih očekivanja stručnjaka vezanih za odnos i saradnju sa porodicom (Zuković, 2012b).

Istraživanja koja su realizovana u proteklih nekoliko decenija su pokazala da poteškoće u razvoju i napredovanju dece često predstavljaju rezultat diskontinuiteta iskustava koja deca dobijaju u porodici i vaspitno-obrazovnoj instituciji, $\mathrm{i}$ to pre svega, u smislu očekivanja i podrške za učenje. Uzroke ovakvog stanja moguće je sagledati kroz prizmu identifikovanja barijera, tj. prepreka za efikasnu saradnju između porodice i vaspitno-obrazovne ustanove. Reč je o strukturalnim i psihološkim barijerama koje se moguće operacionalizovati kroz tri aspekta (Christenson, 2004):

\section{Barijere vezane za porodicu (roditelje)}

- Strukturalne barijere: nedostatak informacija i znanja o značaju partnerskog odnosa, ekonomska, emocionalna i vremenska ograničenja, organizacioni problemi...

- Psihološke barijere: osećanje nekompetentnosti i nedovoljne samoefikasnosti, preuzmanje pasivne uloge $u$ odnosu na obrazovanje nakon uključivanja deteta u vaspitno-obrazovnu instituciju...

\section{Barijere vezane za vaspitno-obrazovnu instituciju (vaspitače/nastavnike)}

- Strukturalne barijere: nedostatak sredstava za finansiranje programa za porodicu, nedovoljna znanja vaspitača/nastavnika o tome kako da stvaraju i održavaju partnerski odnos sa porodicama, vremenska ograničenja...

- Psihološke barijere: nepotpuna opredeljenost za rad sa roditeljima kao partnerima, komunikacija sa roditeljima koja se bazira na kritičkom pristupu, prisutnost stereotipa o porodicama - sumnja u sposobnost porodice/roditelja da se bavi obrazovnim problemima...

\section{Barijere vezane za odnos između porodice $i$ vaspitno-obrazovne institucije}

- Strukturalne barijere: ograničeno vreme za konstrukutivnu komunikaciju i dijalog, komunikacija prevashodno u problemskim situacijama, nedostatak veština i znanja o principima partnerskog delovanja, nedovoljno razumevanje barijere/ograničenja sa kojima se suočava drugi partner...

- Psihološke barijere: nedostatak uverenja da partnerska orijentacija može poboljšati učenje i razvoj deteta, utisci o detetu koji su opservirani samo u 
jednom kontekstu, dominiranje pristupa „pobednik-gubitnik”, umesto pristupa ,pobednik-pobednik”, nesposobnost sagledavanja situacije iz prespektive druge osobe, nedostatak empatije, propust da se razlike vide kao snaga, prethodna negativna iskustva...

Iznošenjem pomenutih barijera naravno nije iscrpljen spisak mogućih prepreka za građenje partnerskih odnosa između porodice i vaspitno-obrazovne institucije, posebno ako se ima u vidu da se problemi vezani za ovu oblast uslovljeni različitošću i specifičnošću, kako porodica, tako i vaspitno-obrazovne institucije. Takođe, treba imati u vidu da su pomenute barije dinamične i međuzavisne, te da stoga, adekvatno i pravovremeno identifikovanje barijera treba da bude rezultat ispitivanja doživljaja i percepcije svih aktera od kojih se očekuje da doprinesu unapređivanju partnerskog odnosa. Posebno je važno da vaspitno-obrazovna instuticija, kao pokretač građenja partnerskih odnosa, dobije saznanja o preprekama vezanim za porodični kontekst kako bi razumela i na adekvatan način odgovorila na očekivanja roditelja vezana za napredovanje njihove dece. S druge strane, neophodno je prevazići prepreke unutar vaspitno-obrazovne instuticije, posebno ako se ima u vidu da su vaspitači/nastavnici i stučni saradnici ti koji stimulativno treba da deluju na proces uključivanja roditelja u život i rad vaspitnoobrazovne instuticije. U svakom slučaju, prisutnost pomenutih barijera treba prevazilaziti na način koji bi omogućio da one postanu prilika za kreiranje uslova koji bi doprineli da porodični i institucionalni kontekst budu stimulativna razvojna okruženja za potencijalno darovito dete.

\section{ZAKLJUČAK}

Vaspitanje i obrazovanje potencijalno darovitog deteta zahteva osetljivost na posebne izazove sa kojima se on suočava i volju da se radi zajedno sa ostalim odraslim osobama koje se bave detetom. Odrasli moraju jasno definisati darovitost, razumeti kako se ona razvija, prepoznati kakve implikacije to ima na planiranje i programiranje vaspitno-obrazovnih aktivnosti. U celini posmatrano, razvijanje specifičnih metoda, programa i načina pomoći i njihova primena suštinski su elementi na putu ostvarivanja punih potencijala deteta. Pri tome je važno naglasiti da ovakav pristup treba da bude zasnovan na efikasnom partnerskom odnosu između porodice i vaspitno-obrazovne ustanove, što podrazumeva usklađivanje porodičnog i institucionalnog vaspitnog modela, koordinisanje konzistentnog rada između roditelja i vaspitača, aktivno uključivanje roditelja u razvijanje programa obogaćivanja. U tom smislu, moguće je sintetizovati određene preporuke koje bi bile temelj za partnersko delovanje porodice i vaspitno-obrazovne institucije (Zuković, 2012b). Reč je, pre svega, o prihvatanju „na dete usmerene filozofije partnerskog pristupa" koja podrazumeva kooperaciju, koordinaciju i kolaboraciju porodice i vaspitno-obrazovne institucije u cilju akademskog, socijalnog, emocionalnog i bihejvioralnog razvoja deteta. Takođe, od suštinskog je značaja 
da porodica i vaspitno-obrazovna institucija zajedno obezbede uslove i sredstva za učenje i napredak dece. Ovakav pristup ne znači propisivanje posebnih uloga i aktivnosti vaspitno-obrazovne institucije i porodice, već podrazumeva podeljenu odgovornost za obrazovanje i socijalizaciju dece, što otvara mogućnosti za zajedničko učešće i delovanje roditelja i stručnjaka. Pritom je veoma važno voditi računa o kvalitetu povezanosti porodice i vaspitno-obrazovne institucije, što zahteva stvaranje konstruktivnog odnosa koji bi omogućio da roditelji i vaspitači/ nastavnici zajedno i na smislen način doprinesu akademskom i socijalnom razvoju dece. Konačno, partnersko delovanje porodice i vaspitno-obrazovne institucije treba da odlikuje usmerenost na preventivni i na rešenje usmereni pristup, koji omogućava da se na adekvatan način kreiraju uslovi koji bi olakšavali i podržavali učenje, napredak i razvoj potencijalno darovitog deteta. 


\title{
SUPPORTING THE DEVELOPMENT OF POTENTIAL GIFTEDNESS IN FAMILY AND INSTITUTIONAL CONTEXTS
}

\begin{abstract}
SUMMARY
Abstract: The paper is based on the premise that high quality experience in family and institutional contexts are very important determinants for giftedness accomplishment. This framework highlights the fact that the paradigm in the fields of education and upbringing has been shifted in the last few decades: from the discourse of academic achievement towards the discourse of human development, from traditional towards the constructivist approach to education and upbringing. The discourse of human development requires education and upbringing to be adapted to the needs, interests and abilities of children; it also requires creating conditions for every child to achieve their full potentials. The interest for studying the quality of growing-up context was prompted also by the formation of social constructivist theory of learning according to which the child's mental activity cannot be separated from the social and cultural context. In addition, the modern educational scene is characterized also by the new ways of understanding child, as well as by considerations regarding the meaning of that new understanding of education. The child is seen as an active and competent being that joins the social context in a completely individual and unique biographical manner. Relying on the new pedagogical picture of the child requires conditions for becoming familiar with individual capabilities and their development, which opens the need for a learning environment that encourages the child's curiosity and interest in the world and for the others. In the light of the above settings, this paper is aimed at understanding the possibility of providing adequate educational support to potentially gifted children in family and institutional context. When it comes to a family context, the paper particularly emphasizes the importance of favourable and stimulating family environment and providing an enriched environment necessary for the development of a potentially gifted child. The paper also highlights the undeniable importance of the parental role, but emphasizes the fact that parents do not create gifted children, but only the atmosphere in which the child can express his talent. With regard to the institutional context, the paper emphasizes that it is the quality of institutional environment of which the quality of children's experience and learning largely depends on, and points to the conditions by which the developmentally appropriate environment is characterized. In this regard, the paper points to kindergartens of Reggio Emilia as stimulating and developmentally appropriate environments, which are examples of how environments in preschool institutions where learning revolves around child's play should look like. In addition to the above, the paper underscores that the efficient, cooperative, partnership-based relationship between the family and educational institution makes a very important factor in the development of potentially gifted children. This perspective is supported by the research which has shown that difficulties in the child's development and advancement are often resulting from the discontinuity of experiences received by children in the family and educational institution in terms of expectations and learning support. Thus, educating and upbringing potentially gifted child requires sensitivity to specific challenges it faces and willingness to work together with other adults who work with the child. Adults need to have giftedness clearly defined, understand how it develops, and identify the implications for planning and programming educational activities.
\end{abstract}

Keywords: development of giftedness, child, family, educational institution, partnership. 


\section{LITERATURA}

Armstrong, T. (2008). Najbolje škole: Kako istraživanje razvoja čovjeka može usmjeravati pedagošku praksu. Zagreb: Educa.

Bašić, S. (2011). (Nova) slika deteta u pedagogiji djetinjstva. U: Maleš, D. (ured.) Nove paradigme ranoga odgoja (str. 19-37). Zagreb: Filozofski fakultet Sveučilišta u Zagrebu - Zavod za pedagogiju.

Christenson, S. L. (2004). The Family-School Partnership: An Opportunity to Promote the Learning Competence of All Students, School Psychology Review, Vol. 33, No. 1, 83-104.

Cowan, R. J., Napolitano, S., Sheridan, S. M. (2004). Home-School Collaboration, Educational Psychology Papers and Publications. Paper 18. Retrieved August 11, 2012 from the World Wide Web: http://digitalcommons.unl.edu/edpsychpapers/18Freeman, 2000.

Freeman, J. (2000). Families, the essential context for gifts and talents. In: K.A. Heller, F.J. Monks, R. Sternberg, R. Subotnik (eds.) International Handbook of Research and Development of Giftedness and Talent (pp. 573-585). Oxford: Pergamon Press.

George, D. (2005). Obrazovanje darovitih: kako identificirati i obrazovati darovite $i$ talentirane učenike. Zagreb: Educa.

Klemenović, J. (2009). Savremeni predškolski programi. Novi Sad: Savez pedagoških društava Vojvodine; Vršac: Visoka škola strukovnih studija za obrazovanje vaspitača „Mihailo Palov".

Lai, Y. (2009). Reconsidering the Education of Gifted Young Children with the Reggio Emilia Approach. Exceptionality Education International, 19(3), 96-110.

Maleš, D. (2011). Uvod. U: Maleš, D. (ured.) Nove paradigme ranoga odgoja (str. 7-11). Zagreb: Filozofski fakultet Sveučilišta u Zagrebu - Zavod za pedagogiju.

Miljak, A. (2007). Teorijski okvir sukonstrukcije kurikuluma ranog odgoja. U: Previšić, V. (ured.) Kurikulum: teorije - metodologija - sadržaj-struktura (str. 205-252). Zagreb: Zavod za pedagogiju Filozofskog fakulteta, Školska knjiga.

Milutinović, J. (2011). Socijalni konstruktivizam u oblasti obrazovanja i učenja. Zbornik Instituta za pedagoška istraživanja, 43(2), 177-194.

Milutinović, J., Zuković, S. (2008). Razumevanje i razvoj darovitosti: značaj porodice. U: (ur. G. Gojkov) Porodica kao faktor podsticanja darovitosti. Zbornik 14 (424 - 434). Vršac: Visoka škola strukovnih studija za obrazovanje vaspitača „Mihailo Palov“_-Vršac.

Pavlović Breneselović, D. (2014). Partnerstvo sa porodicom: tri paradigme, dva modela, jedna ili više stvarnosti. U: Identitet profesije pedagog u savremenom obrazovanju, Zbornik radova (111- 116). Beograd: Filozofski fakultet.

Pekić, J. (2012). Vaspitni postupci roditelja kao činioci aktualizacije darovitosti. Godišnjak Filozofskog fakulteta u Novom Sadu, knjiga XXXVII, 201-213.

Petrović-Sočo, B. (2011). Nova paradigma shvaćanja konteksta ustanova ranoga odgoja. U: Maleš, D. (ured.) Nove paradigme ranoga odgoja (str. 237-264). Zagreb: Filozofski fakultet Sveučilišta u Zagrebu - Zavod za pedagogiju.

Ristić, Ž. (2006). O istraživanju, metodu i znanju. Beograd: Institut za pedagoška istraživanja.

Rotigel, J. V. (2003). Understanding the Young Gifted Child: Guidelines for Parents, Families, and Educators, Early Childhood Education Journal, Vol. 30. No. 4. 209-214. 
Sekulić-Majurec, A. (1995). Darovita djeca i obitelj: istine i zablude, Društvena istraživanja, 4-5, 551-561.

Sweeney, S. N. (1995). Gifted Children Have Special Needs Too. Early Childhood News, 7(3), Vujičić, L. (2011). Novi pristup istraživanju kulture vrtića. U: Maleš, D. (ured.) Nove paradigme ranoga odgoja (str. 209-236). Zagreb: Filozofski fakultet Sveučilišta u Zagrebu - Zavod za pedagogiju.

Zuković, S., Milutinović, J. (2006). Ciljevi obrazovanja i podrška darovitim u porodici. U: Gojkov, G. (ured.) Darovitost, interakcija i individualizacija u nastavi. Zbornik 12 (str. 164-172). Vršac: Viša škola za obrazovanje vaspitača - Vršac; Rumunija, Temišvar: Univerzitet „Tibiscus”.

Zuković, S. (2012a). Porodica kao sistem - funkcionalnost i resursi osnaživanja. Novi Sad: Pedagoško društvo Vojvodine.

Zuković, S. (2012b). Odnos između porodice i škole: od saradnje ka partnerstvu. U: O. Gajić (ur.) Kvalitet obrazovnog sistema Srbije u evropskoj perspektivi, Zbornik radova/knjiga 2, (219-230). Novi Sad: Filozofski fakultet.

Zuković, S., Milutinović, J. (2013). Metodološki aspekti istraživanja porodice kao sredinskog faktora razvoja darovitosti. U: G. Gojkov \& A. Stojanović (ur.): Metodološki problemi istraživanja darovitosti, Zbornik 18 (409-416). Vršac: Visoka škola strukovnih studija za obrazovanje vaspitača „Mihailo Palov”- Vršac; Arad: Universitatea de Vest „Aurel Vlaicu.

11-13. 